\title{
Inhibitory effects of lysozyme on endothelial protein C receptor shedding in vitro and in vivo
}

\author{
Sae-Kwang Ku $\mathrm{K}^{1, \#}$, Eun-Kyung Yoon ${ }^{2, \#}$, Hyun Gyu Lee, ${ }^{3, \#}$ Min-Su Han ${ }^{4}$, Taeho Lee ${ }^{2, *} \mathcal{E} J o n g-S u p ~ B a e^{2, *}$ \\ ${ }^{1}$ Department of Anatomy and Histology, College of Korean Medicine, Daegu Haany University, Gyeongsan 38610, Korea, ${ }^{2}$ College of \\ Pharmacy, CMRI, Research Institute of Pharmaceutical Sciences, Kyungpook National University, Daegu 41566, Korea, ${ }^{3}$ Department of \\ Microbiology and Immunology, Yonsei University College of Medicine, Seoul 03722, Korea, ${ }^{4}$ Laboratory for Arthritis and Bone Biology, \\ Fatima Research Institute, Daegu Fatima Hospital, Daegu 41199, Korea
}

\begin{abstract}
Lysozyme protects us from the ever-present danger of bacterial infection and binds to bacterial lipopolysaccharide (LPS) with high affinity. Beyond its role in the activation of protein $\mathrm{C}$, the endothelial cell protein $C$ receptor (EPCR) plays an important role in the cytoprotective pathway. EPCR can be shed from the cell surface, which is mediated by tumor necrosis factor- $\alpha$ converting enzyme (TACE). However, little is known about the effects of lysozyme on EPCR shedding. We investigated this issue by monitoring the effects of lysozyme on phorbol12-myristate 13-acetate (PMA)-, tumor necrosis factor (TNF)- $\alpha$-, interleukin (IL)-1 $\beta$-, and cecal ligation and puncture (CLP)-mediated EPCR shedding and underlying mechanism. Data demonstrate that lysozyme induced potent inhibition of PMA-, TNF- $\alpha-$, IL-1 $\beta-$, and CLP-induced EPCR shedding. Lysozyme also inhibited the expression and activity of PMA-induced TACE in endothelial cells. These results demonstrate the potential of lysozyme as an anti-EPCR shedding reagent against PMA-mediated and CLP-mediated EPCR shedding. [BMB Reports 2015; 48(11): 624-629]
\end{abstract}

\section{INTRODUCTION}

Endothelial protein C receptor (EPCR) is one of the type I trans-membrane protein with homology to CD1/MHC class I trans-membrane proteins which are engaged in vascular inflammation (1). As a receptor to protein C (PC) and activated protein C (APC) with the high binding affinity to them, EPCR has a anticoagulant and anti-inflammatory functions $(2,3)$. The anti-

*Corresponding authors. Taeho Lee, Tel: +82-53-950-8573; Fax: +82-53-950-8557; E-mail: tlee@knu.ac.kr, Jong-Sup Bae, Tel: +82-53-950-8570; Fax: +82-53-950-8557; E-mail: baejs@knu.ac.kr ${ }^{\text {"}}$ These authors contributed equally to this work.

http://dx.doi.org/10.5483/BMBRep.2015.48.11.038

Received 2 March 2015, Revised 24 March 2015, Accepted 22 April 2015

Keywords: CLP, EPCR shedding, Lysozyme, Vascular inflammation, coagulant pathway of APC is induced by the activated blood coagulation factors $\mathrm{Va}$ and VIIla with the involvement of protein S, high-density lipoproteins, phosphatidylserine, cardiolipin, and glucosylceramide (4). The cytoprotective functions of APC such as anti-inflammatory, anti-apotosis, and vascular barrier protective, is mediated by EPCR and the protease-activated receptor-1 (PAR-1) (4).

By EPCR shedding processes, a soluble form of EPCR (sEPCR) can be generated in vitro through proteolytic cleavage by metalloprotease activity, which is inducible by several inflammatory mediators $(5,6)$. Circulating EPCR in plasma could bind to both APC and PC, but could not enhance the activation of PC to APC (7). And, sEPCR suppresses APC's anticoagulant activity via the formation of a complex that does not bind to phospholipid membranes (8). Owing to the shedding of membrane EPCR, sEPCR can be detected in plasma at a concentration of approximately $100 \mathrm{ng} / \mathrm{mL}$, and high levels of sEPCR have been reported in systemic inflammatory diseases (9). Previous in vitro reports showed a significant increase sEPCR in endothelial cells by a variety of vascular inflammatory inducers such as interleukin (IL)-1 $\beta$, hydrogen peroxide, and phorbol myristate acetate (PMA), and thrombin, and EPCR shedding is potentiated by nocodazole $(5,6,10)$. And, the activation of p38 MAPK, ERK1/2, and JNK was mediated by PMA (11-13), and activation of tumor necrosis factor- $\alpha$ converting enzyme (TACE) occurs upon activation of ERK or p38 $(14,15)$.

Lysozymes thwart bacterial growth and are found in relatively high concentration in blood, saliva, tears, and milk (16). Lysozyme is a small protein that protects us from the ever-present danger of bacterial infection by attacking the cell walls of bacteria $(17,18)$. Cell wall of bacteria, composed of carbohydrate chains, braces their delicate membrane against the cell's high osmotic pressure and lysozyme breaks these carbohydrate chains, which leads to the rupturing of the bacteria under their own internal pressure $(17,18)$.

Lysozyme is one of the powerful first-line defenses against bacterial infection, where microorganisms are most likely to enter the body $(17,18)$. However, to date, the effects of lysozyme on EPCR shedding have not yet been studied. Thus, noting that lysozyme has a pleiotropic role in bacterial defense, and that

ISSN: 1976-670X (electronic edition)

Copyright (c) 2015 by the The Korean Society for Biochemistry and Molecular Biology

(ㄷ) This is an open-access article distributed under the terms of the Creative Commons Attribution Non-Commercial License (http://creativecommons.org/licenses/by-nc/4.0) which permits unrestricted non-commercial use, distribution, and reproduction in any medium, provided the original work is properly cited. 
shedding of EPCR is accompanied with the disruption of vascular integrity and the main pathophysiology of sepsis $(9,19)$, we hypothesized that lysozyme might inhibit the shedding of EPCR. Now, we report evidence to support our hypothesis.

\section{RESULTS AND DISCUSSION}

\section{Effect of lysozyme on PMA-, TNF- $\alpha-$, or IL-1 $\beta$-induced EPCR} shedding

Previous studies have demonstrated the PMA stimulation of EPCR shedding from human umbilical vein endothelial cells (HUVECs) $(20,21)$. In agreement with those studies, our results show that $1 \mu \mathrm{m}$ PMA fully stimulated EPCR shedding from HUVECs (Fig. 1A), and induced a decrease in membrane EPCR on HUVECs (Fig. 1B). To investigate the effect of lysozyme on PMA-mediated EPCR shedding, HUVECs were pretreated with increasing concentrations of lysozyme for $6 \mathrm{~h}$, followed by stimulation with $1 \mu \mathrm{m}$ PMA for $1 \mathrm{~h}$. Results showing that lysozyme inhibited EPCR shedding induced by PMA in HUVECs, with an op- timal effect at 20-200 nm are presented in Fig. 1A and B. However, lysozyme alone had no effect on EPCR shedding (Fig. $1 \mathrm{~A}, \mathrm{~B})$. Therefore, lysozyme alone did not affect the expression of membrane-bound EPCR. To confirm the inhibitory effects of lysozyme on EPCR shedding, TNF- $\alpha$ or IL- $1 \beta$ was used because previous reports have shown that EPCR shedding was induced by TNF- $\alpha$ or IL-1 $\beta$ in HUVECs (11). We found that EPCR shedding induced by TNF- $\alpha$ or IL-1 $\beta$ increased and that lysozyme suppressed TNF- $\alpha$-mediated (Fig. 1C) or IL-1 $\beta$-mediated EPCR shedding (Fig. 1D) in HUVECs. Because endothelial cells exhibit differences in gene and protein expression according to their vascular bed of origin, we used human pulmonary artery endothelial cells to confirm the anti-EPCR shedding effects of lysozyme against PMA-, TNF- $\alpha-$, or IL-1 $\beta$-induced EPCR shedding (data not shown). Because TNF- $\alpha$ and IL-1 $\beta$ have been shown to be important mediators of endotoxemia $(22,23)$, the current findings showing that lysozyme inhibited TNF- $\alpha$-mediated or IL-1 $\beta$-mediated EPCR shedding could support the notion that lysozyme has anti-inflammatory effects in human endothelial cells.
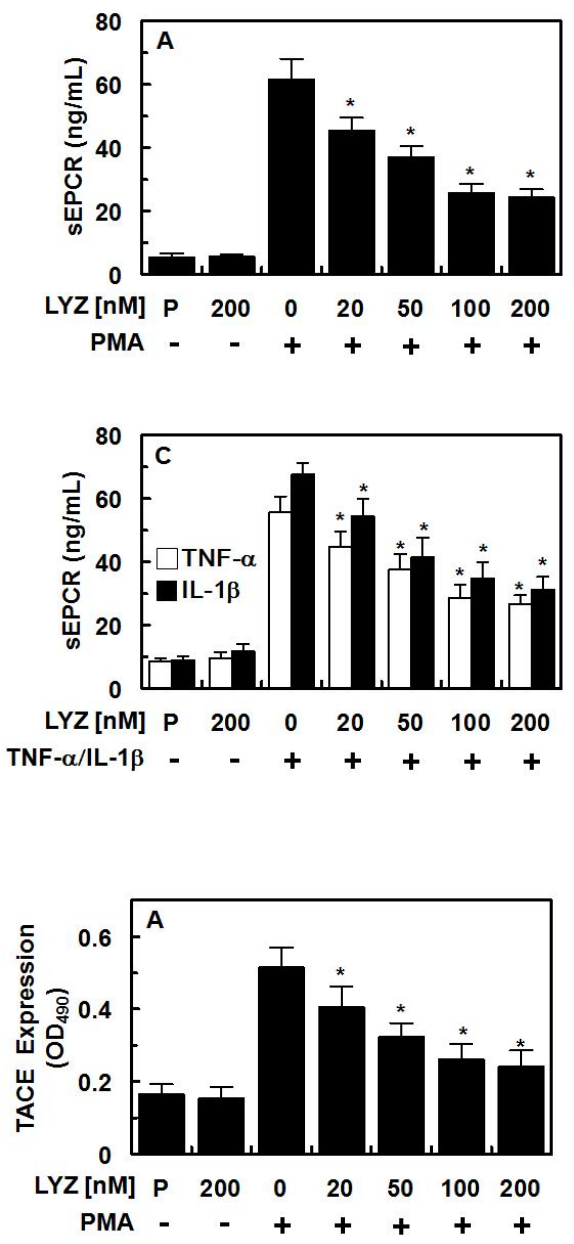

Fig. 1. Effect of lysozyme on PMA-, TNF- $\alpha$-, and IL-1 $\beta$-induced EPCR shedding. The effects of various concentrations of lysozyme on PMA $(1 \mu \mathrm{m})$-induced EPCR shedding were monitored by the measurement of $s E P C R$ (A) or membrane EPCR on HUVECS (B) and after HUVEC incubation with TNF- $\alpha$ (C, $25 \mathrm{ng} / \mathrm{mL}$ for $1 \mathrm{~h}$, white bar) or IL-1 $\beta$ (D, $25 \mathrm{ng} / \mathrm{mL}$ for $1 \mathrm{~h}$, black bar). " $\mathrm{P}$ " in each X-axis means vehicle (PBS) only. Results are expressed as the mean \pm SEM of three separate experiments. *P $<0.05$ vs. PMA alone (A, B), TNF- $\alpha(C$ $\mathrm{D})$, or IL-1 $\beta$ alone $(\mathrm{C}, \mathrm{D})$. 


\section{Effects of lysozyme on PMA-stimulated expression and} activity of TACE

Previously, TACE mediates PMA-stimulated EPCR shedding (21). To verify if lysozyme can suppress the expression and activity of TACE by PMA, HUVECs were stimulated with PMA after treated with lysozyme. Data showed that lysozyme inhibited TACE expression by PMA (Fig. 2A). PMA-induced TACE activity was also inhibited by lysozyme (Fig. 2B).

Effect of lysozyme on CLP-induced EPCR shedding, protein C concentration, and thrombin generation

To confirm the effects of lysozyme on EPCR shedding in mice, we used a CLP model because this model could mimic severe human vascular inflammatory diseases, sepsis (24-26). To determine the trend in mortality caused by CLP, groups of septic and sham-operated mice were monitored for survival for $132 \mathrm{~h}$ ( $>$ five days). The survival rate of mice subjected to CLP was $20 \%$ at $80 \mathrm{~h}$ and $0 \%$ at $100 \mathrm{~h}$ post operation (Fig. 3A). In CLP-operated mice, histological data showed the decreased expresson of membrane EPCR compared to controls (Fig. 3B). Injection of lysozyme at a single dose $(2.86 \mu \mathrm{g} /$ mouse, $12 \mathrm{~h}$ after CLP) could not inhibit EPCR shedding by CLP (Fig. 3C). Thus, lysozyme was injected two times (once at $12 \mathrm{~h}$, then at $50 \mathrm{~h}$ post CLP), resulting in a decrease in EPCR shedding (Fig.
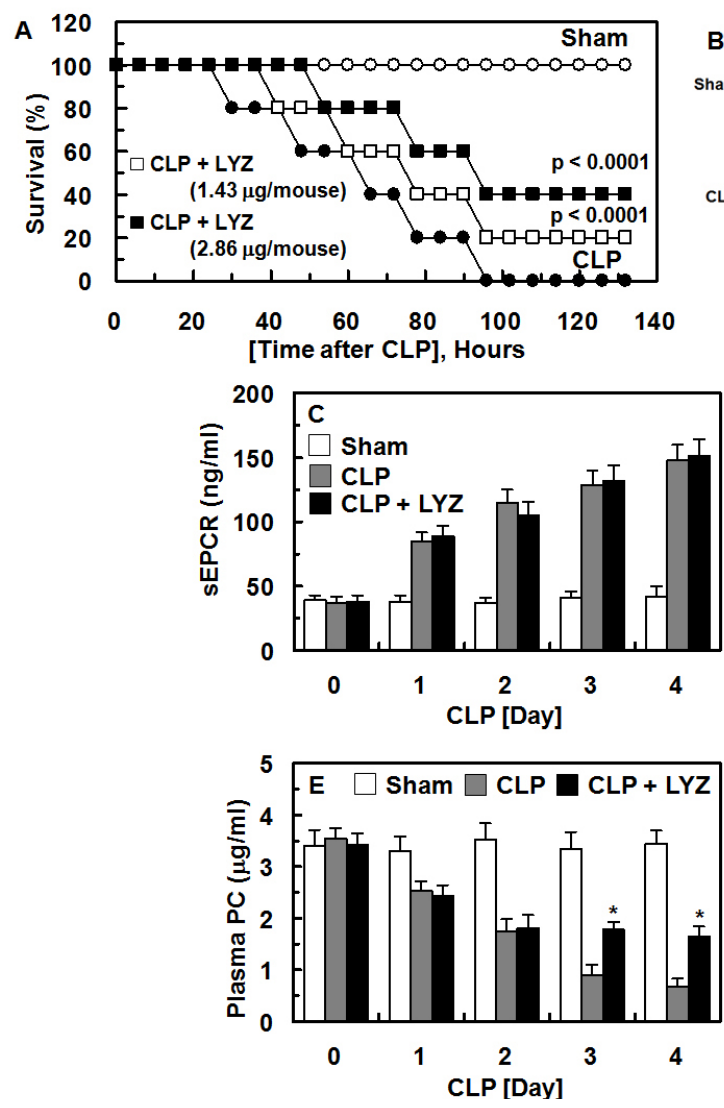

EPCR

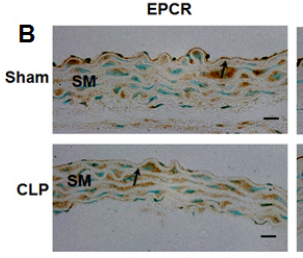

, Endothelial cells; SM, Smooth muscle cells; CD31, EC marker
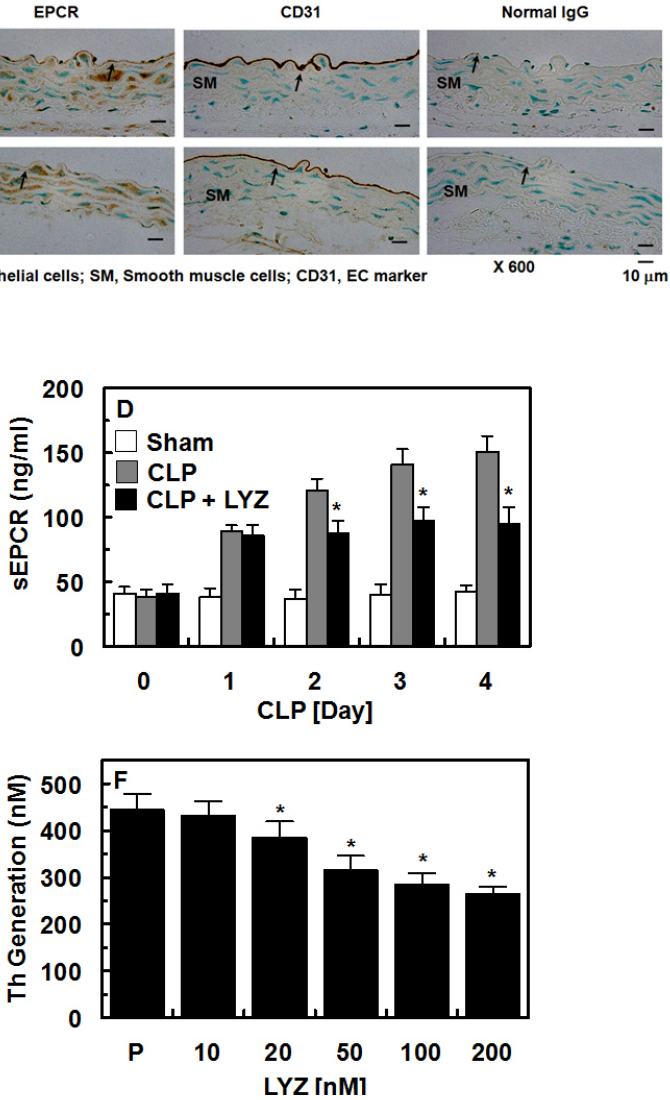

Fig. 3. Effect of lysozyme on CLP-induced mortality, EPCR shedding, PC concentrations, and thrombin generation. (A) Male C57BL/6 mice (n $=20)$ were administered intravenously with lysozyme $(1.43 \mu \mathrm{g} / \mathrm{mouse}, \square)$ or $(2.86 \mu \mathrm{g} / \mathrm{mouse}, \boldsymbol{\square})$ at $12 \mathrm{~h}$ and $50 \mathrm{~h}$ after CLP. Animal survival was monitored every $6 \mathrm{~h}$ after CLP for $132 \mathrm{~h}$. Control CLP mice $(\boldsymbol{O})$ and sham-operated mice $(\bigcirc)$ were administered sterile saline. A Kaplan-Meier survival analysis was used for the determination of overall survival rates vs. CLP treated mice. (B) Immunohistochemical staining of the descending thoracic aortic vessel for membrane EPCR from CLP-operated mice was compared with results from sham-operated mice. Results are representative of 3-6 staining processes from 3 independent experiments per condition. (C-E) Serum was obtained from sham-operated (white bar) or CLP-induced septic mice (gray bar) on the indicated day after CLP surgery ( $\mathrm{n}=5$ each group) on different days for different mice. Lysozyme (black bar, $2.86 \mu \mathrm{g} /$ mouse) was administered once (C, $12 \mathrm{~h}$ after CLP) or twice (D and $\mathrm{E}$, once $12 \mathrm{~h}$, then $50 \mathrm{~h}$ after CLP) on different days for different mice. EPCR shedding was then monitored by measurement of sEPCR $(C, D)$ and plasma PC was determined by ELISA (E). (F) HUVEC monolayers were pre-incubated with FVa $(100 \mathrm{pM})$ and FXa (1 nM) for 10 min with the indicated concentrations of lysozyme. Prothrombin was added to a final concentration of $1 \mu \mathrm{m}$ and prothrombin activation was determined 30 min later, as described in the "Materials and Methods" section. "P" in each X-axis indicates vehicle (PBS) only. All results are expressed as the mean \pm SEM of three separate experiments. ${ }^{*} \mathrm{P}<0.05$ vs. CLP alone $(\mathrm{C}-\mathrm{E})$ or vs. $\mathrm{P}(\mathrm{F})$. 
3D). It is well known that average circulating blood volume for mice is $72 \mathrm{ml} / \mathrm{kg}$ (27). As the average weight of used mice in this study is $27 \mathrm{~g}$, and the average blood volume is $72 \mathrm{~mL} / \mathrm{kg}$ $(2 \mathrm{ml} / 27 \mathrm{~g})$, the amount of lysozyme ( $2.86 \mu \mathrm{g}$ per mouse) injected yielded a maximum concentration of $100 \mathrm{~nm}$ in the peripheral blood, which was determined by ELISA. Based on these findings, we hypothesized that treatment with lysozyme could reduce the CLP-induced sepsis lethality. Administration of lysozyme $(1.43 \mu \mathrm{g}$ or $2.87 \mu \mathrm{g} /$ mouse, once at $12 \mathrm{~h}$, then at $50 \mathrm{~h}$ after CLP) resulted in an increase in the survival rate to $20-40 \%$ ( $P<0.0001$, Fig. 3A). This result suggests that the suppression of EPCR shedding provides a therapeutic strategy for the management of sepsis.

The main enzyme in the PC-mediated negative feedback mechanism is APC, which proteolytically cleaves FVa and FVIIla to inhibit the generation of thrombin and subsequent fibrin formation $(4,28)$. PC is converted to APC by the interaction of thrombin and thrombomodulin $(4,28)$. Therefore, we tested the effects of lysozyme on PC concentration. The data show that plasma PC levels were significantly attenuated in CLP-operated mice and administration of lysozyme suppressed the CLP-induced decrease in PC levels (Fig. 3E). In addition, activation of the coagulation cascade appears to be an essen- tial component in the development of multi-organ failure in sepsis (29).

Therefore, we tested the effects of lysozyme on the generation of thrombin in HUVECs. Previous report showed that HUVECs are able to support the activation of prothrombin by factor Xa (FXa) (30). Here, pre-incubation of HUVECs with FVa and $\mathrm{FXa}$ in the presence of $\mathrm{CaCl}_{2}$ prior to addition of prothrombin resulted in production of thrombin (Fig. 3F). And, treatment with lysozyme inhibited the production of thrombin from prothrombin by dose-dependent manner (Fig. 3F). Lysozyme at $200 \mathrm{~nm}$ did not have antibacterial activity, which excludes the possibility that the inhibition of EPCR shedding, TACE activity, and thrombin generation by lysozyme is not due to the antibacterial activity of lysozyme (data not shown).

\section{Effects of lysozyme on PMA-stimulated phosphorylation of p38 MAPK, ERK1/2, and JNK}

Previous studies have reported the involvement of p38 MAPK, ERK1/2, and JNK in cytokine-induced EPCR shedding, and increased phosphorylation of p38 MAPK, ERK1/2, and JNK has been known to occur via PMA stimulation (11-13). Therefore, in order to determine the molecular mechanisms underlying the suppression of PMA-induced EPCR shedding by lysozyme, the
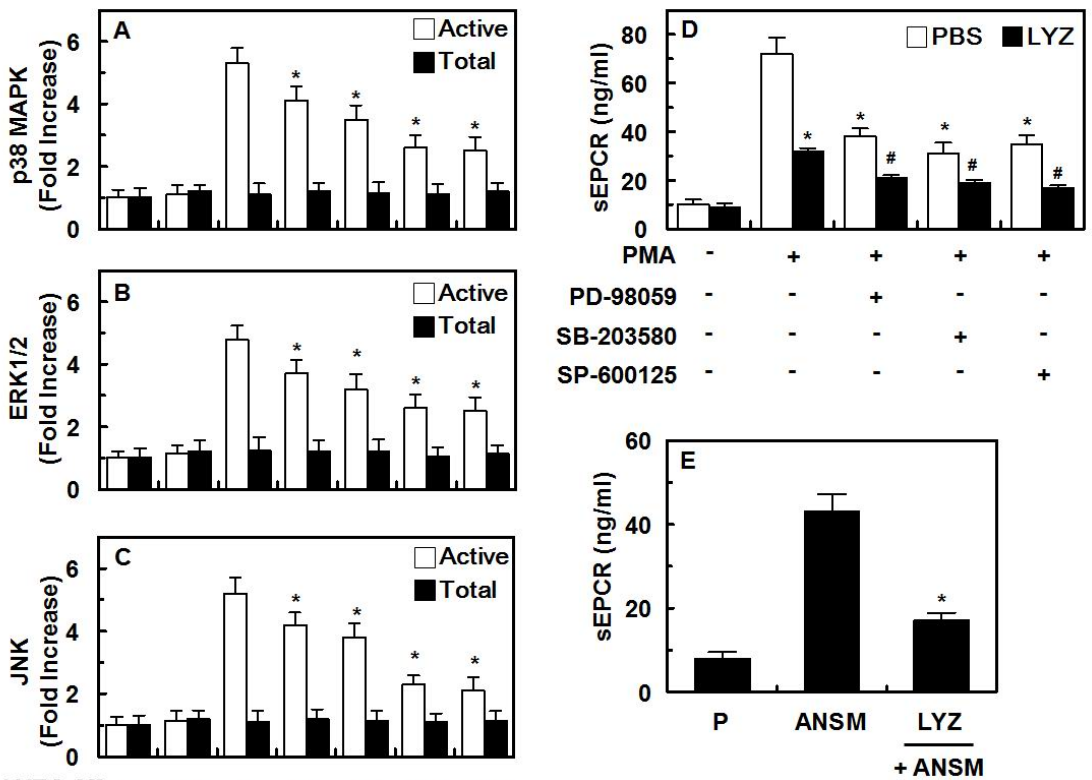

Fig. 4. Effect of lysozyme on PMA-induced phosphorylation of p38 MAPK, ERK1/2, and JNK. (A-C) PMA (1 $\mu$ m, 1h)-mediated phosphorylation of phospho-p38 MAPK (A; white bar), total p38 MAPK (A; black bar), phospho-ERK1/2 (B; white bar) or total ERK1/2 (B; black bar) and phospho-JNK ( $\mathrm{C}$; white bar) or total JNK ( $\mathrm{C}$; black bar) was analyzed after the treatment of cells with lysozyme. Results are expressed as fold increases over control values. (D) Cells were pre-incubated with $50 \mu \mathrm{m}$ PD-98059, $10 \mu \mathrm{m}$ SB-203580, or $20 \mu \mathrm{m}$ SP-600125 as indicated for 30 min with or without lysozyme at $100 \mathrm{nM}$ each and thereafter exposed to PMA at a final concentration of $1 \mu \mathrm{m}$ for an additional $1 \mathrm{~h}$. EPCR shedding was monitored by measurement of sEPCR ELISA. (E) The effects of lysozyme at $100 \mathrm{nM}$ each on Anisomycin (ANSM, $5 \mu \mathrm{m}, 4$ h)-induced EPCR shedding were monitored by the measurement of sEPCR. "P" in each X-axis indicates vehicle (PBS) only. All results are expressed as the mean \pm SEM of three separate experiments. ${ }^{*} \mathrm{P}<0.05$ vs. PMA (A-D) alone, ANSM (H) alone, or ${ }^{*} \mathrm{P}<0.05$ vs. white bar (D). 
effects of lysozyme on the PMA-stimulated phosphorylation of p38 MAPK, ERK1/2, and JNK were tested. As shown in Fig. $4 \mathrm{~A}-\mathrm{C}$, treatment with lysozyme resulted in a reduction in PMA-stimulated phosphorylation of p38 MAPK (Fig. 4A), ERK1/2 (Fig. 4B), and JNK (Fig. 4C). A panel of pharmacological inhibitors of MAP kinases was used to confirm the involvement of MAPK in EPCR shedding. As shown in Fig. 4D, a distinct attenuation of $s E P C R$ release in HUVECs was observed after treatment with PD-98059 (a pharmacological inhibitor of ERK 1/2 activity), SB-203580 (an inhibitor of p38 MAPK), and SP-600125 (an inhibitor of JNK). We also found synergistic anti-EPCR shedding effects of each MAP kinase inhibitor with lysozyme on the PMA-mediated EPCR shedding (Fig. 4D). Furthermore, MAP kinase signaling pathways such as JNK and p38 are directly targeted by lysozyme in response to stimulation of EPCR shedding because anisomycin (activator of JNK and p38 MAPK)-mediated EPCR shedding is reduced by lysozyme (Fig. 4E).

As the increased phosphorylation of p38 MAPK, ERK1/2, and JNK is known to occur via PMA stimulation (11-13) and the activation of TACE occurs upon activation of ERK or p38 MAPK (14, 15), we aimed to determine the processes responsible for the inhibition of PMA-stimulated EPCR shedding and expression of TACE by lysozyme. To do this we investigated the involvement of MAPK signaling pathways under PMA- stimulated conditions. MAPKs comprise a family of highly conserved serine/threonine protein kinases that are believed to play key roles in the mediation of inflammation (31). Three major classes of MAPKs are represented by ERK $1 / 2$ and the stress-activated protein kinase families, JNK and p38 MAPK. As shown in Figs. 2 and 4, lysozyme inhibited the responses of PMA-stimulated expression of TACE and phosphorylation of p38 MAPK, ERK1/2, and JNK. Therefore, lysozyme inhibited EPCR shedding via the inhibition of the PMA-stimulated expression of TACE and the activation of MAPKs.

Collectively, the results of this study show that lysozyme potently inhibited PMA-, TNF- $\alpha-$, IL-1 $\beta$ - and CLP-induced EPCR shedding and suppressed the expression and activity of TACE (Supplementary Fig. 1). Lysozyme also suppressed the CLP-induced PC decrease in mice and thrombin generation in HUVECs. In addition, lysozyme reduced PMA-stimulated phosphorylation of p38 MAPK, ERK 1/2, and JNK. TACE induced the shedding of a large number of cell membrane-bound proteins, and in the present study, EPCR shedding was also shown to be mediated by TACE, which was inhibited by lysozyme. Selective targeting and inhibition of sEPCR by lysozyme in the endothelium against several inducers such as PMA, TNF- $\alpha, \mathrm{IL}-1 \beta$, and CLP, affords promise for severe vascular inflammatory diseases such as sepsis. However, pharmacological and pharmaceutical factors such as adsorption to the endothelium, distribution, metabolism, and excretion are major hurdles to overcome before lysozyme's therapeutic potential can be fully realized. Although the use of lysozyme for therapeutic purposes could have non-specific effects, the data presented in this study provide novel information on the role of lysozyme in EPCR shedding.
Therefore, our findings indicate the potential of lysozyme as a candidate for the treatment of severe vascular inflammatory diseases, such as sepsis and septic shock.

\section{MATERIALS AND METHODS}

\section{Reagents}

Lysozyme from chicken egg white (L7651), anisomycin, and IL-1 $\beta$ were purchased from Sigma-Aldrich (St. Louis, MO). sEPCR and TNF- $\alpha$ were purchased from Abnova (Taiwan). FVa, FXa, prothrombin, and thrombin were obtained from Haematologic Technologies (Essex Junction, VT).

\section{Cell culture}

Primary HUVECs were obtained from Cambrex Bio Science (Charles City, IA) and maintained as previously described (10, 26,32 ). HUVECs from passage 3 or 4 were used in the subsequent experiments.

\section{TACE activity assay}

For the TACE activity assay, a commercially available TACE activity kit (Innozyme TACE activity assay kit, EMD Millipore, Billerica, MA) was used as described previously $(10,33)$.

\section{Thrombin production on the surface of HUVECs}

Measurement of thrombin production by HUVECs was quantified as previously described $(34,35)$.

\section{Competitive ELISA for SEPCR and TACE}

The concentrations of SEPCR and TACE were measured as described previously (10).

\section{Statistical analysis}

All experiments were performed independently at least three times. Values are expressed as mean \pm standard error of the mean (SEM). The statistical significance of differences between test groups was evaluated by one-way analysis of variance (ANOVA) and Tukey's post-hoc test. SPSS for Windows, version 16.0 (SPSS, Chicago, IL) was used to perform statistical analysis, and statistical significance was accepted for $P$ values $<0.05$.

\section{ACKNOWLEDGEMENTS}

This study was supported by the National Research Foundation of Korea (NRF) funded by the Korea government [MSIP] (Grant No. 2012R1A5A2A42671316) and by Basic Science Research Program through the National Research Foundation of Korea (NRF) funded by the Ministry of Science, ICT \& Future Planning (NRF-2014R1A2A1A11052798).

\section{REFERENCES}

1. Esmon CT (2006) The endothelial protein C receptor. Curr Opin Hematol 13, 382-385 
2. Fukudome K and Esmon CT (1994) Identification, cloning, and regulation of a novel endothelial cell protein C/activated protein C receptor. J Biol Chem 269, 26486-26491

3. Stearns-Kurosawa DJ, Kurosawa S, Mollica JS, Ferrell GL and Esmon CT (1996) The endothelial cell protein C receptor augments protein $\mathrm{C}$ activation by the thrombin-thrombomodulin complex. Proc Natl Acad Sci U S A 93, 10212-10216

4. Mosnier LO, Zlokovic BV and Griffin JH (2007) The cytoprotective protein C pathway. Blood 109, 3161-3172

5. Xu J, Qu D, Esmon NL and Esmon CT (2000) Metalloproteolytic release of endothelial cell protein C receptor. J Biol Chem 275, 6038-6044

6. Lee W, Ku SK and Bae JS (2013) Emodin-6-O-beta-D-glucoside down-regulates endothelial protein $\mathrm{C}$ receptor shedding. Arch Pharm Res 36, 1160-1165

7. Kurosawa S, Stearns-Kurosawa DJ, Hidari N and Esmon CT (1997) Identification of functional endothelial protein $\mathrm{C}$ receptor in human plasma. J Clin Invest 100, 411-418

8. Liaw PC, Neuenschwander PF, Smirnov MD and Esmon CT (2000) Mechanisms by which soluble endothelial cell protein $\mathrm{C}$ receptor modulates protein $\mathrm{C}$ and activated protein $\mathrm{C}$ function. J Biol Chem 275, 5447-5452

9. Kurosawa S, Stearns-Kurosawa DJ, Carson CW, D'Angelo A, Della Valle P and Esmon CT (1998) Plasma levels of endothelial cell protein $\mathrm{C}$ receptor are elevated in patients with sepsis and systemic lupus erythematosus: lack of correlation with thrombomodulin suggests involvement of different pathological processes. Blood 91, 725-727

10. Ku SK, Han MS, Lee MY, Lee YM and Bae JS (2014) Inhibitory effects of oroxylin A on endothelial protein $\mathrm{C}$ receptor shedding in vitro and in vivo. BMB Rep 47, 336-341

11. Menschikowski $M$, Hagelgans $A$, Eisenhofer $G$ and Siegert G (2009) Regulation of endothelial protein C receptor shedding by cytokines is mediated through differential activation of MAP kinase signaling pathways. Exp Cell Res 315, 2673-2682

12. Han H, Du B, Pan X et al (2010) CADPE inhibits PMA-stimulated gastric carcinoma cell invasion and matrix metalloproteinase-9 expression by FAK/MEK/ERK-mediated AP-1 activation. Mol Cancer Res 8, 1477-1488

13. Leng Y, Steiler TL and Zierath JR (2004) Effects of insulin, contraction, and phorbol esters on mitogen-activated protein kinase signaling in skeletal muscle from lean and ob/ob mice. Diabetes 53, 1436-1444

14. Huovila AP, Turner AJ, Pelto-Huikko M, Karkkainen I and Ortiz RM (2005) Shedding light on ADAM metalloproteinases. Trends Biochem Sci 30, 413-422

15. Murphy G (2008) The ADAMs: signalling scissors in the tumour microenvironment. Nat Rev Cancer 8, 929-941

16. Kelly JA, Sielecki AR, Sykes BD, James MN and Phillips DC (1979) X-ray crystallography of the binding of the bacterial cell wall trisaccharide NAM-NAG-NAM to lysozyme. Nature 282, 875-878

17. Clingolani R (2014) Bioinspired approaches for human-centric technologies. Springer, New York

18. Nakimbugwe D, Masschalck B, Deckers D, Callewaert L, Aertsen A and Michiels CW (2006) Cell wall substrate specificity of six different lysozymes and lysozyme inhibitory activity of bacterial extracts. FEMS Microbiol Lett 259,
41-46

19. Borgel D, Bornstain C, Reitsma PH et al (2007) A comparative study of the protein $C$ pathway in septic and nonseptic patients with organ failure. Am J Respir Crit Care Med 176, 878-885

20. Qu D, Wang Y, Song Y, Esmon NL and Esmon CT (2006) The Ser219--> Gly dimorphism of the endothelial protein C receptor contributes to the higher soluble protein levels observed in individuals with the A3 haplotype. J Thromb Haemost 4, 229-235

21. Qu D, Wang Y, Esmon NL and Esmon CT (2007) Regulated endothelial protein $\mathrm{C}$ receptor shedding is mediated by tumor necrosis factor-alpha converting enzyme/ADAM17. J Thromb Haemost 5, 395-402

22. Michie HR, Manogue KR, Spriggs DR et al (1988) Detection of circulating tumor necrosis factor after endotoxin administration. N Engl J Med 318, 1481-1486

23. Kremer JP, Jarrar D, Steckholzer U and Ertel W (1996) Interleukin-1, -6 and tumor necrosis factor-alpha release is down-regulated in whole blood from septic patients. Acta Haematol 95, 268-273

24. Buras JA, Holzmann B and Sitkovsky M (2005) Animal models of sepsis: setting the stage. Nat Rev Drug Discov 4, 854-865

25. Yang H, Ochani M, Li J et al (2004) Reversing established sepsis with antagonists of endogenous high-mobility group box 1. Proc Natl Acad Sci U S A 101, 296-301

26. Bae JS, Lee W, Nam JO, Kim JE, Kim SW and Kim IS (2014) Transforming Growth Factor beta-induced Protein Promotes Severe Vascular Inflammatory Responses. Am J Respir Crit Care Med 189, 779-786

27. Diehl KH, Hull R, Morton D et al (2001) A good practice guide to the administration of substances and removal of blood, including routes and volumes. J Appl Toxicol 21, $15-23$

28. Weiler H (2011) Multiple receptor-mediated functions of activated protein C. Hamostaseologie 31, 185-195

29. Wang L, Bastarache JA and Ware LB (2008) The coagulation cascade in sepsis. Curr Pharm Des 14, 1860-1869

30. Sugo T, Nakamikawa C, Tanabe S and Matsuda M (1995) Activation of prothrombin by factor Xa bound to the membrane surface of human umbilical vein endothelial cells: its catalytic efficiency is similar to that of prothrombinase complex on platelets. J Biochem 117, 244-250

31. Thalhamer T, McGrath MA and Harnett MM (2008) MAPKs and their relevance to arthritis and inflammation. Rheumatology (Oxford) 47, 409-414

32. Ku SK and Bae JS (2014) Antithrombotic activities of sulforaphane via inhibiting platelet aggregation and FIla/FXa. Arch Pharm Res 37, 1454-1463

33. Miller MA, Meyer AS, Beste MT et al (2013) ADAM-10 and -17 regulate endometriotic cell migration via concerted ligand and receptor shedding feedback on kinase signaling. Proc Natl Acad Sci U S A 110, E2074-2083

34. Bae JS (2011) Antithrombotic and profibrinolytic activities of phloroglucinol. Food Chem Toxicol 49, 1572-1577

35. Kim TH, Ku SK and Bae JS (2012) Antithrombotic and profibrinolytic activities of eckol and dieckol. J Cell Biochem $113,2877-2883$ 